\section{COMPLEX LIVES}

Evidence from Kenya's Olorgesailie Basin suggests that early humans developed trading networks and evolved other complex behaviours when the climate was becoming more variable.

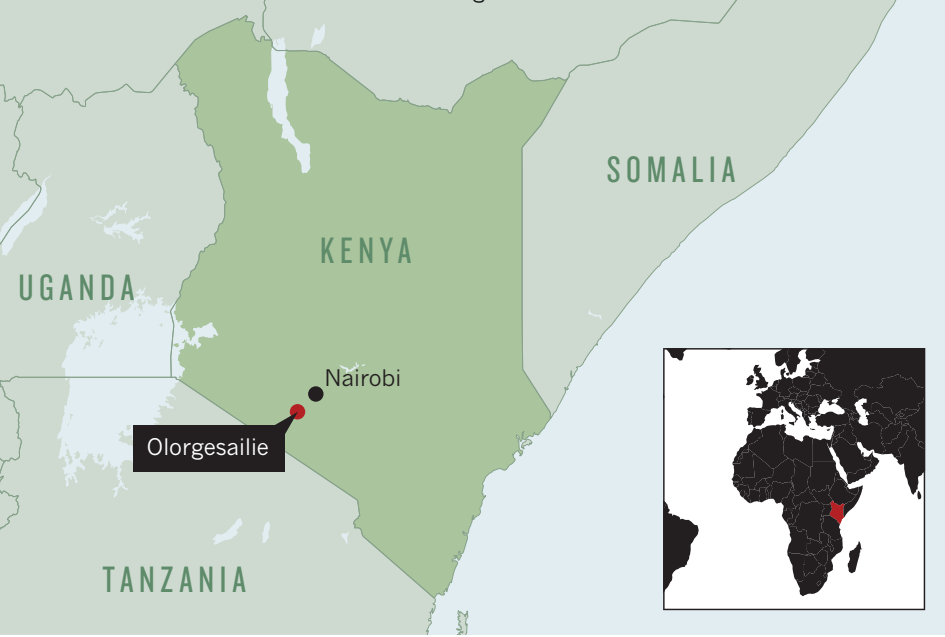

University of Arizona in Tempe, says he isn't yet convinced by the evidence for trade. "To demonstrate extended social networks, I would like to see regular and systematic transport of raw material across a number of artefact types on the order of 100 kilometres," he says.
The team cannot say exactly how long before 320,000 years these changes happened because an extended period of erosion at the site wiped out the archaeological record there between 499,000 and 320,000 years ago.

Some information could come from several projects that drilled into ancient lake beds in Kenya and Ethiopia to collect a detailed record of environmental and ecological changes in the region ${ }^{6}$. Potts and his team drilled two of those cores in the southern Olorgaseilie Basin, and Potts says the cores cover the entire period that is missing from the archaeological record. Comparisons with cores drilled elsewhere in East Africa should help scientists to differentiate between events happening locally and broader regional climatic trends.

"The drill cores I hope will be a game changer, because of the precision of the environmental record and hopefully the precision of the dating," Potts says. Then it's a matter of working to understand how animals and people might have responded to the changing environment, Potts says. "Only then can we say anything about how climate is really affecting human evolution."

1. Potts, R. et al. Science http://dx.doi.org/10.1126/ science.aao2200 (2018).

2. Deino, A. L. et al. Science http://dx.doi. org/10.1126/science.aao2216 (2018)

3. Brooks, A. S. et al. Science http://dx.doi. org/10.1126/science.aao2646 (2018).

4. Hublin, J.-J. et al. Nature 546, 289-292 (2017)

5. Blegen, N. J. Hum. Evol. 103, 1-19 (2017).

6. Cohen, A. et al. Sci. Dril. 21, 1-16 (2016).

\title{
POLITICS
}

\section{China creates grand science ministry}

\section{Reforms sparkfears that fundamental research will suffer.}

\section{BY DAVID CYRANOSKI}

$\longrightarrow$ hinese leaders released plans last week to expand the powers of the country's science and technology ministry (MOST). The beefed-up agency will continue to oversee science policy and major projects, but will take on extra responsibilities for funding research grants and for recruiting foreign scientists. Politicians say that the reforms will streamline government procedures, but some science-policy experts warn that the changes could weaken support for basic research.

The announcement came at the annual assembly of the National People's Congress in Beijing, where the government revealed that more than 15 ministries and agencies will be merged, restructured or abolished. The National Natural Science Foundation of China (NSFC), the major grant-funding agency, will no longer sit under the powerful State Council, but will be managed by the science ministry.

Other agency changes include expanding the office that oversees intellectual property, creating a ministry of ecological environment to monitor pollution and forming a conservation agency to help in the protection of endangered species, such as the Przewalski's gazelle (Procapra przewalskii).

The plans to expand the science ministry will have the biggest impact on researchers, and took many Chinese scientists by surprise. The NSFC funds modestly sized competitive grants that are initiated by individual investigators. In 2016 , its budget of 26.8 billion yuan (US $\$ 3.9$ billion) accounted for nearly one-third of China's basic research funding, and was used to support 44,000 research projects. The science ministry, by contrast, manages large projects that are aligned with national goals. Scientists often criticize the ministry for supporting projects on the basis of political and personal connections, rather than expert advice. "Placing NSFC under MOST is likely to complicate these missions," says Cao Cong, a science-policy researcher at the University of Nottingham in Ningbo, China.
Cao, who met with science-ministry colleagues last week, says that many didn't seem to know about the reshuffling. "The reorganization was kept in the dark until the last minute," he says.

Cao says that the reforms could be a sign that the Chinese leadership is unhappy with the progress of the country's previous major reorganization of science, in 2014, which attempted to streamline competitive funding.

The repercussions of the latest reforms will take time to unfold, Cao says. But one scenario is that the NSFC will gradually lose control over basic-research funding, says Cao. "If so, the entire scientific community will be unhappy," he says. NSFC grants are highly regarded by scientists because they are peer-reviewed and place less emphasis on scientists' personal connections. They're also one of the only sources of funding for new $\mathrm{PhD}$ students.

Many prominent Chinese researchers say that China's basic-research spending is already too low compared with that of other nations that invest heavily in science. In 2017, China spent 92 billion yuan on basic research, or $0.1 \%$ of its gross domestic product (GDP). The United States invests $0.2 \%$ of its GDP in basic science.

The NSFC's new head, Li Jinghai, who took over the reins last month, told Nature that details about the integration of MOST and the NSFC "need to be discussed and figured out in the coming months". But he said the State Council had promised more money for basic science in a document released in January. "I am sure that basic science in China will be further strengthened," he says. 


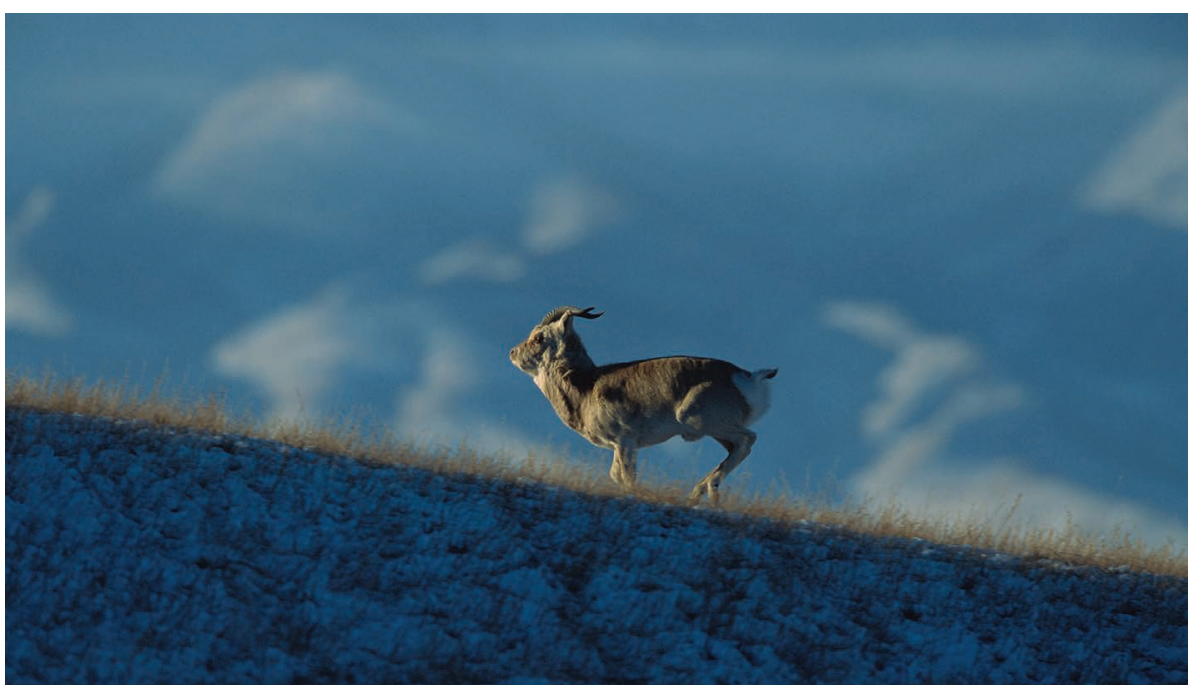

The endangered Przewalski's gazelle comes under the remit of the new conservation ministry.

Wang Yifang, director of the Institute of High Energy Physics in Beijing and a member of the National People's Congress, has high hopes for the merger. He has been an outspoken critic of China's process for selecting major scientific projects, saying that peer reviewers sometimes don't have appropriate expertise. Wang wants China to adopt a system more like that in the United States, where expert groups assess the quality of projects.
Conservationists also welcomed plans to create new ministries to protect the environment. The government said an ecology ministry will monitor pollution and enforce environmental-protection laws, and a ministry of natural resources will manage conservation.

Environmentalists say the revamped structure should reduce conflicts between ministries that have similar areas of responsibility. For instance, under the current structure, grasslands are managed by the agriculture ministry, whereas the wildlife on the grasslands is the responsibility of the State Forestry Administration. As a result, in Qinghai province in central China, the forestry administration has tried to remove fences in grasslands to link up isolated Przewalski's gazelle populations at the same time as the agriculture ministry has funded the construction of new fences. "It's one ecosystem. [It] needs to be addressed as a whole," says Zhang Li, a conservation biologist at Beijing Normal University.

Zhang says that a lack of coordination between agencies has also meant that China's endangered-species list has not been updated for ten years. For instance, the current list designates the Chinese pangolin (Manis pentadactyla) — a scaly mammal — and the Yangtze finless porpoise (Neophocaena asiaeorientalis asiaeorientalis) as vulnerable to extinction. But the pangolin population has plummeted because of illegal hunting for traditional Chinese medicine and the International Union for Conservation of Nature (IUCN) now lists it as critically endangered. Zhang says that protections for the porpoises, also critically endangered on the IUCN list, should also be strengthened.

Zhang expects that the new natural-resources ministry will update the endangered species list in the near future. 